\title{
Analytic Hierarchy Process Application for the Selection of a Metal Matrix Composite
}

\author{
Sergio Baragetti*
}

\author{
Centre on Innovation Management and Technology Transfer, SMLab - Structural Mechanics Lab, Department of \\ Engineering, Università degli Studi di Bergamo, Via Salvecchio 19, 24129 Bergamo, Italy
}

\begin{abstract}
The multi-attribute decision-making methods allow to solve arbitrary problems governed by several parameters. In this paper, the choice of a composite material was analyzed, by considering the availability from four companies. The multi-attribute decision Analytic Hierarchy Process (AHP) procedure was used to select the best levels for different attributes, both parametric and non-parametric, and to select the best company.
\end{abstract}

Keywords: Analytic Hierarchy Process (AHP), decision-making methods, metal matrix composites.

\section{INTRODUCTION}

The production of composite materials falls within the "special processes" [1-3] category, which is important for the continuous monitoring of the process parameters. In practice, it is not possible to separate the calculation and optimization of the product from the production phase, as the parameters that affect the latter demand preliminary analysis and optimization during the design process. The optimization of the design and the production of mechanical components made of composite materials requires therefore to search for new methods of analysis, which allow to address the choice of the parameters and provide an effective procedure that enables the assignment of an index of the product quality. These methods must take into account the relative importance and the interactions between the various design and construction parameters, such as cost, purchased material characteristics, availability of processing factors. Moreover, since many parameters affect the processes of design and construction of the mechanical components made of composite materials, it is mandatory to take care in first place of the quality analysis of the supply, the availability of materials and the costs. To this field belongs the research, the adoption and the optimization of methods for the material selection, to assess and weigh the various factors affecting the purchase phase of the material. The methodology for Multi-Attribute Decision Making (MADM) is divided into elementary multi-criteria methodologies (score and lexicographic method) such as Multiple Attribute Utility Theory (MAUT) method, Analytic Hierarchy Process (AHP), Fuzzy Multi-Attribute Decision Making (FMADM), and "outranking" interactive methods. In particular, the Analytic Hierarchy Process (AHP) methodology [3-13] has been found to be the most suitable for the evaluation of the supplies of different companies producing materials and

*Address correspondence to this author at the Centre on Innovation Management and Technology Transfer, SMLab - Structural Mechanics Lab, Department of Engineering, Università degli Studi di Bergamo, Via Salvecchio 19, 24129 Bergamo, Italy; Tel: +39/0352052382-082-281;

E-mail: sergio.baragetti@unibg.it metal matrix composites reinforced by alumina hard particles in different percentages [14-16].

The aim of this paper is to provide the designer with a practical tool that allows the selection of a particulate metal matrix composite material by considering the mechanical parameters, costs and availability offered by different dealers. This paper reports the application of a general procedure that any machine designer could use, without targetting at a specific application. Many other parameters, such as "corrosion resistance" and "ease of machinability", might to be added, targetting at specific applications.

\section{FUNDAMENTAL PARAMETERS (QUALITY INDEXES) FOR THE MATERIAL SELECTION}

The most relevant parameters for the material selection have been divided into three different categories: mechanical characteristics, costs, availability.

The density of the material is used in the definition of the parameters related to the mechanical characteristics, since this factor seems to be important for the choice of the material itself. The considered factors are listed below:

\section{- Mechanical Properties}

1) Modulus of longitudinal elasticity $\mathrm{E}$, obtainable from tensile tests. This feature is very important, since the particle reinforced composite is chosen primarily for the high stiffness increase it offers. The ratio $\frac{E}{\rho}$

(where $\mathrm{E}$ is the modulus of longitudinal elasticity expressed in $\mathrm{MPa}$ and $\rho$ is the material density in $\left.\mathrm{kg} / \mathrm{m}^{3}\right)$ is defined. The ratio is then normalized by imposing an optimal value of $\mathrm{E}$ (reference) equal to $10^{5} \mathrm{MPa}$, as well as the density of the material, constant and equal to $2900 \mathrm{~kg} / \mathrm{m}^{3}$.

2) Percentage elongation at break $\mathrm{A} \%$. An optimum value (reference) of elongation percentage equal to $10 \%$ is imposed, therefore the quality index takes the value 1 when $\mathrm{A}=10 \%$. 
3) $\frac{R_{m}}{\rho}$ ratio, where $\mathrm{R}_{\mathrm{m}}$ is the ultimate tensile strength in $\mathrm{MPa}$, obtainable from tensile tests, and $\rho$ is the material density in $\mathrm{kg} / \mathrm{m}^{3}$. The ratio is normalized by requiring that the density is constant and equal to $2900 \mathrm{~kg} / \mathrm{m}^{3}$ for the test material (otherwise, if this parameter is variable, a reference density can be defined) and that the optimal value of the breaking load is equal to $400 \mathrm{MPa}$.

4) $\frac{R_{s}}{\rho}$ ratio, where $\mathrm{R}_{\mathrm{s}}$ is the yield strength in $\mathrm{MPa}$ obtainable from tensile test and $\rho$ is the material density equal to $2900 \mathrm{~kg} / \mathrm{m}^{3}$. A reference value for the material yield strength, equal to $350 \mathrm{MPa}$, and a constant density, equal to $2900 \mathrm{~kg} / \mathrm{m}^{3}$, are imposed, coherently with step 3 .

5) $\frac{\sigma_{F A}}{\rho}$ ratio, where $\sigma_{\mathrm{FA}}$ is the fatigue strength of the material for alternating load, in MPa, as measured by rotating bending fatigue tests with hourglass specimens, following the ISO 1143 requirements, and $\rho$ is the density of the material in $\mathrm{kg} / \mathrm{m}^{3}$. Since this index is defined as in step 3, a reference value of the fatigue limit of the material equal to $200 \mathrm{MPa}$, and a constant density equal to $2900 \mathrm{~kg} / \mathrm{m}^{3}$ are imposed.

6) Material uniformity, defined as a measure of a more or less homogeneous dispersion of the particles within the matrix, estimated by analyzing flat sections cut from some samples of the material. In order to estimate the homogeneity of the material, plane sections of area of $0.01 \mathrm{~mm}^{2}$ (for example, a square cross section of side $0.1 \mathrm{~mm}$ ) are examined by means of optical microscopy. The sections can be obtained from the extruded bars of W6A20A. From these sections, the total number of clusters of particles of size greater than $100 \mu \mathrm{m}$ (the reinforcing particles have an average size of $20 \mu \mathrm{m}$ ), as well as the number of clusters of particles with maximum size exceeding $100 \mu \mathrm{m}$ for each section, can be determined. From the analysis, the values of $N_{100 \mu m}$, i.e. the total number of clusters larger than $100 \mu \mathrm{m}$, and of $N_{100 \mu \operatorname{mmax}}$, i.e. the maximum number of clusters larger than $100 \mu \mathrm{m}$ found in a section, are derived. The following indexes can be defined:

a) $\frac{N_{100 \mu m}}{n}$, by imposing $\mathrm{n}=10$ and a reference value of $N_{100 \mu m}$ equal to 1 , the index takes the value 1 when the ratio is equal to 0.1 .

b) $\frac{N_{100 \mu m \max }}{n}$, by imposing $\mathrm{n}=10$ and a reference value of $N_{100 \mu m \max }$ equal to 1 , the index takes the value 1 when the ratio is equal to 0.1 .

\section{Cost of the material}

1) Cost of material produced in extruded round bars.

2) Payment Terms.

3) Change in the cost depending on the amount of material required.

- Availability of the material

1) Time required for the production and shipment of extruded bars of the selected material (as the order is received).

\section{"ANALYTIC HIERARCHY PROCESS" AND CHOICE OF THE MATERIAL}

The Analytic Hierarchy Process [3-13] was applied to the material selection, by assuming that it is produced in Italy by four companies, denominated for the sake of simplicity as A, B, C, D, with mechanical characteristics, costs and availability defined as follows. Table $\mathbf{1}$ shows the mechanical properties for the four companies.

Table 2 reports the values of the normalized quality indexes related to the mechanical characteristics, for the four considered companies.

Table 3 shows the material cost data for the four considered fictitious companies.

Table 4 reports the values of the data related to the material availability for the four considered companies.

\section{CRITERIA FOR THE APPLICATION OF THE "ANALYTIC HIERARCHY PROCESS (AHP)" TO THE MATERIAL SELECTION}

The first step is to define the aim of the search, or goal, while evaluating the different alternatives. In particular, for the choice of the composite material, the main goal is to identify the most suitable material based to specific needs. The alternatives are between the material manufacturers in Italy, i.e. the four companies denominated as A, B, C, D. Once the goal, under which the different alternatives must be evaluated, as well as the alternatives themselves, are defined, it is necessary to identify the basic parameters, i.e. the selection criteria for the choice of the material. The parameters are reported below, in one or more hierarchical categories, arranged at different levels, depending on their importance and their belonging to different decision criteria. In practice, by means of a schematic tree, the attributes are listed in the order they belong to a superior parameter. Therefore, in the problem of the choice of a material that uses a single category hierarchy, the main criterion for selection is the end of the research, i.e. the material choice. The second level presents the mechanical properties, the cost and the availability of same materials, while the third level lists the parameters strictly dependent from the second level attributes. For example, regarding the mechanical characteristics second level attribute, the third level presents the parameters $\frac{\mathrm{E}}{\rho}, \mathrm{A} \%, \frac{R_{s}}{\rho}, \frac{R m}{\rho}$, $\frac{\sigma_{F A}}{\rho}, \frac{N_{100 \mu m}}{n}, \frac{N_{100 \mu m \max }}{n}$. 
Table 1. Mechanical characteristics for the four manufacturers of the composite material.

\begin{tabular}{|c|c|c|c|c|c|c|c|}
\hline & $\mathbf{A} \%$ & $\mathbf{E}[\mathbf{M P a}]$ & $\mathbf{R}_{\mathbf{m}}[\mathbf{M P a}]$ & $\mathbf{R}_{\mathbf{s}}[\mathbf{M P a}]$ & $\boldsymbol{\sigma}_{\mathrm{FA}}$ & $\boldsymbol{N}_{\mathbf{1 0 0} \boldsymbol{\mu m}}$ & $\boldsymbol{N}_{\mathbf{1 0 0} \boldsymbol{\mu} \boldsymbol{m} \text { max }}$ \\
\hline \hline A & 4 & 92830 & 370 & 318 & 160 & 8 & 2 \\
\hline B & 5 & 95000 & 350 & 300 & 140 & 12 & 1 \\
\hline C & 7 & 88000 & 385 & 330 & 170 & 5 & 1 \\
\hline D & 9 & 80000 & 360 & 305 & 150 & 9 \\
\hline
\end{tabular}

Table 2. Values of the normalized quality indexes, related to the mechanical characteristics, for the four fictitious companies.

\begin{tabular}{|c|c|c|c|c|c|c|c|}
\hline & A\% & $\frac{\mathbf{E}}{\rho}$ & $\frac{\boldsymbol{R}_{m}}{\rho}$ & $\frac{\boldsymbol{R}_{s}}{\rho}$ & $\frac{\sigma_{F A}}{\rho}$ & $\frac{N_{100 \mu m}}{n}$ & $\frac{N_{100 \mu \max }}{n}$ \\
\hline B & 5 & 0.95 & 0.87 & 0.85 & 0.7 & 12 & 1 \\
\hline $\mathrm{C}$ & 7 & 0.88 & 0.96 & 0.94 & 0.85 & 5 & 1 \\
\hline
\end{tabular}

Table 3. Data related to the material costs for the four considered companies.

\begin{tabular}{|c|c|c|c|}
\hline & $\begin{array}{c}\text { Material Cost in Extruded Round Bars } \\
{[\boldsymbol{\epsilon} / \mathrm{kg}]}\end{array}$ & Terms of Payment [Days] & $\begin{array}{c}\text { Change in Cost with the Amount of } \\
\text { Material [\% Reduction for Every 1000 kg] }\end{array}$ \\
\hline \hline A & 180 & 60 & 10 \\
\hline B & 150 & 30 & 12 \\
\hline C & 165 & 30 & 11 \\
\hline D & 150 & 60 & 10 \\
\hline
\end{tabular}

Table 4. Data on the availability of material for the four considered companies.

\begin{tabular}{|c|c|}
\hline & Delivery Time [Days] \\
\hline \hline A & 15 \\
\hline B & 20 \\
\hline C & 15 \\
\hline D & 30 \\
\hline
\end{tabular}

Subsequently, for each defined level in the hierarchy, priorities are assigned to different parameters level by level, according to the importance assumed by the same parameters with respect to the decision criterion of the next higher level. For example, in the cost category it must be determined which one of the three cost parameters, i.e. 1) the cost of the material extruded bars, 2) the payment terms, and 3) changes in the cost with the amount of material, assumes a greater importance with respect to the other two, and it is necessary to establish the order of importance of three parameters.

To judge the importance of different parameters residing at the same hierarchical level, a grading scale is adopted, where the various possibilities of mutual significance, which different parameters may have between themselves, are classified in numeric terms (scale of 1 to 9 ). Table $\mathbf{5}$ shows

Table 5. Comparison of the numerical terms for parameters evaluation and literal meaning.

\begin{tabular}{|c|c|c|}
\hline Importance & Definition & Explanation \\
\hline \hline $\mathbf{1}$ & Equal importance & The two parameters have the same importance within the same hierarchical level \\
\hline $\mathbf{3}$ & Moderate importance & A parameter is considered to be moderately more important than the other \\
\hline $\mathbf{5}$ & High importance & A parameter is considered to be more important than the other \\
\hline $\mathbf{7}$ & Very high importance & A parameter is believed to be much more important than the other \\
\hline $\mathbf{9}$ & Extreme importance & A parameter has extreme importance related to each other \\
\hline $\mathbf{2 , 4 , 6 , 8}$ & Intermediate importance between the previous values & Judgent of importance is intermediate between those reported \\
\hline
\end{tabular}


the comparison of numerical terms and the meaning that they assume. If a parameter has an importance of 5 with respect to another parameter, the latter has an importance equal to $1 / 5$ with respect to the first. From this consideration, a "matrix of importance" or "array of priorities" is built for each different level of the hierarchy, as well as for all the parameters related to an attribute dependent on the same upper level, thus assessing the priority relations that exist between the different adopted parameters in pairs.

The priorities are then calculated for each parameter, by summing the numerical values for each row associated with the analyzed parameter, and comparing them to the total sum, the sum of the priorities being equal to one. The importance scores between the parameters at the same level must take into account also the importance of the parameters on which they depend in the upper level. In our case, the priority set for the first level is equal to 1 , and the sum of the priorities of the second and third level must be equal to 1 .

Then, to the last level (but this can be done at any level as well), the best alternative is selected, by analyzing the different parameters separately, and building priority matrices, in which the priorities of the various alternatives between the different parameters levels are calculated.

At this point, it can be decided which of the alternatives (A, B, C, D) is the best, by building a table which shows the values of the parameters of the priority level for the judgment (in this case the final one) and the values of the priorities of the alternatives calculated for each parameter of the selected level.

To obtain the values of the effective priority for each alternative, since this is a function of the priorities of the different parameters, it is mandatory to multiply the values of the priorities of the individual parameters for the priorities of the alternatives, before calculating the final sum. The best alternative will be given from the maximum sum of the priorities $n_{i}$, evaluated for the different parameters. To assess the priorities of the individual parameters, located at different levels of the category hierarchy shown in Fig. (1), the program "Expert Choice" has been used [12].

The program allows to evaluate the decision inconsistency during the evaluation of the priorities of the different parameters, by setting the parameter "consistency ratio" obtained for each comparison matrix. Remember that a judgment is inconsistent if it leads to incorrect equalities: if, for example, $\mathrm{x}=3 \mathrm{y} \mathrm{x}=5 \mathrm{z}$, then it must be $5 / 3 \mathrm{z}=\mathrm{y}$, i.e. the parameter $y$ has a relative importance with respect to the parameter $\mathrm{z}$ equal to $5 / 3$. In this case, the comparison judgment will be inconsistent if the relative importance will take on a different value than $5 / 3$.

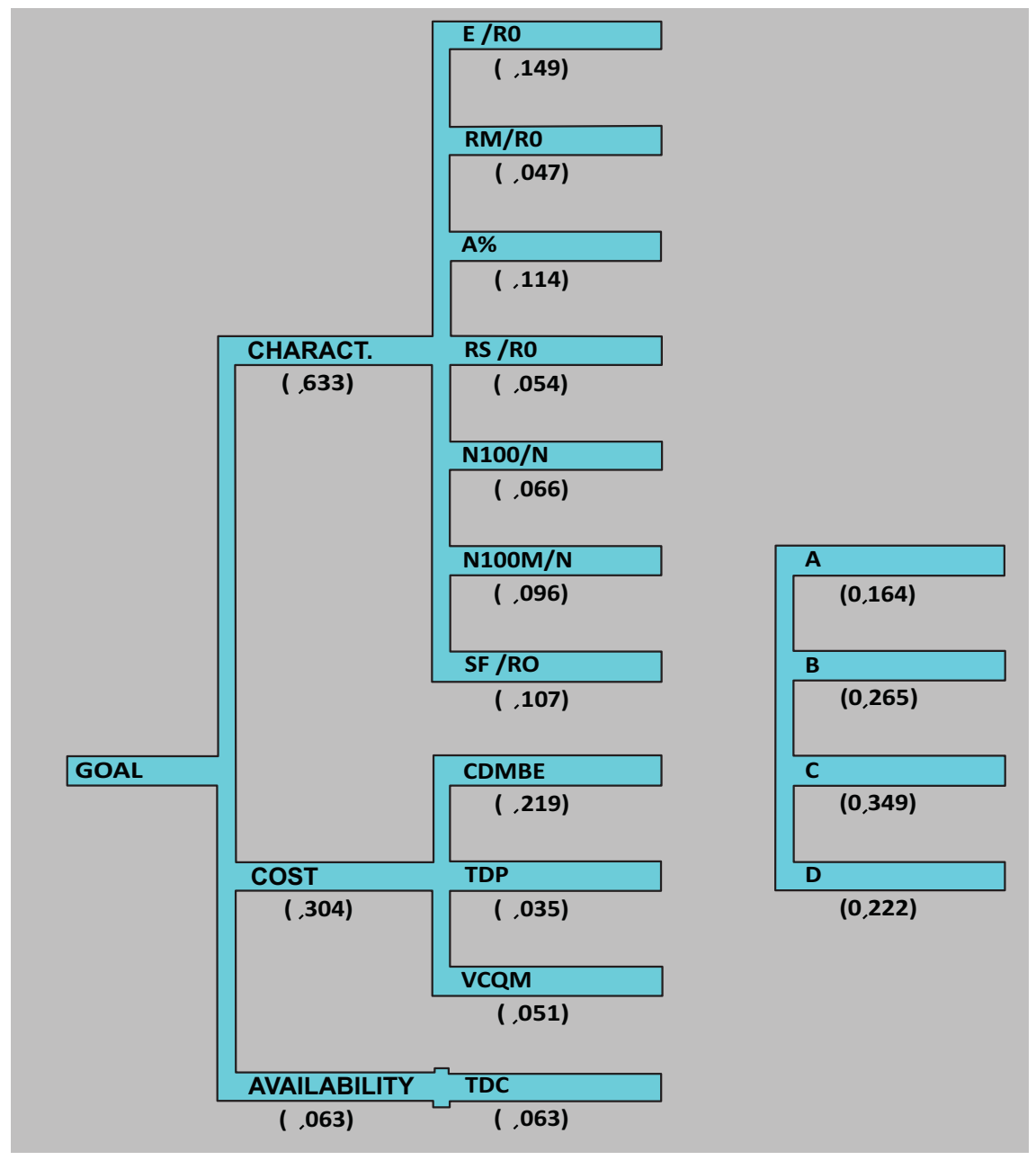

Fig. (1). Hierarchical category for the selection of the composite material and priorities for individual parameters. 


\section{RESULTS OF THE ANALYSIS CONDUCTED BY THE AHP METHOD}

Fig. (1) shows the class hierarchy for the selection of composite materials and lists the different priorities (evaluated using the criterion of judgment proposed by the AHP methodology and described in Table 5) for the individual parameters, which define the class hierarchy itself.
Fig. (2) shows the comparison table for the second level of the class hierarchy and priorities and highlights the relevant coefficient of inconsistency.

Fig. (3) shows the comparison matrix for the mechanical parameters, on the third level of the class hierarchy, with relative priorities and the coefficient of inconsistency. In Figs. $(4,5)$, the priorities are assessed at the local level and the sum must be equal to 1 . Fig. (3) priorities are evaluated at the global level, hence the sum of the priority for the

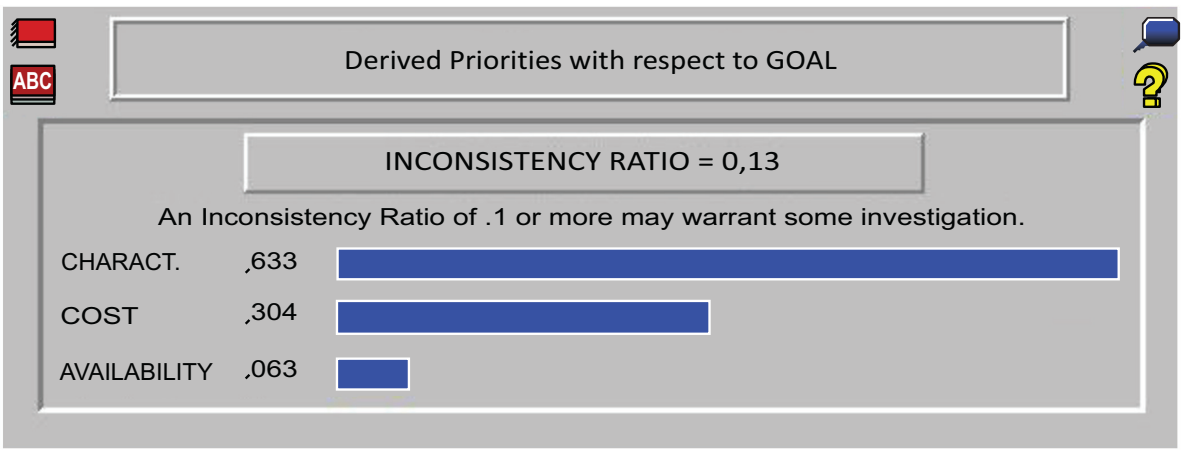

Fig. (2). Comparison matrix for the second level of the class hierarchy, priorities, and its coefficient of inconsistency.

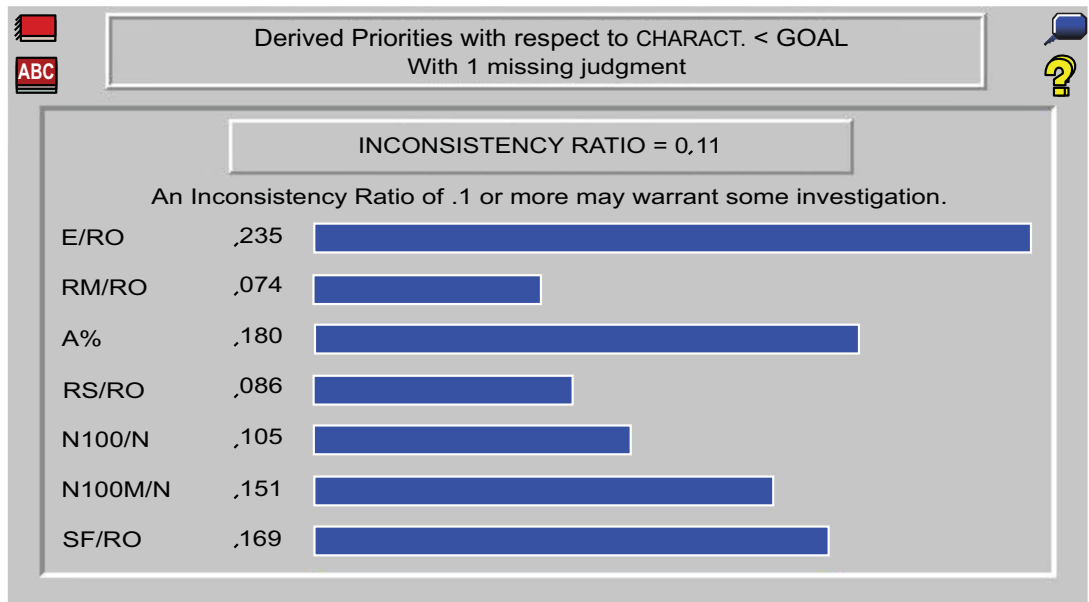

Fig. (3). Comparison matrix for the mechanical parameters on the third level of the class hierarchy, with parameter priorities and related coefficient of inconsistency.

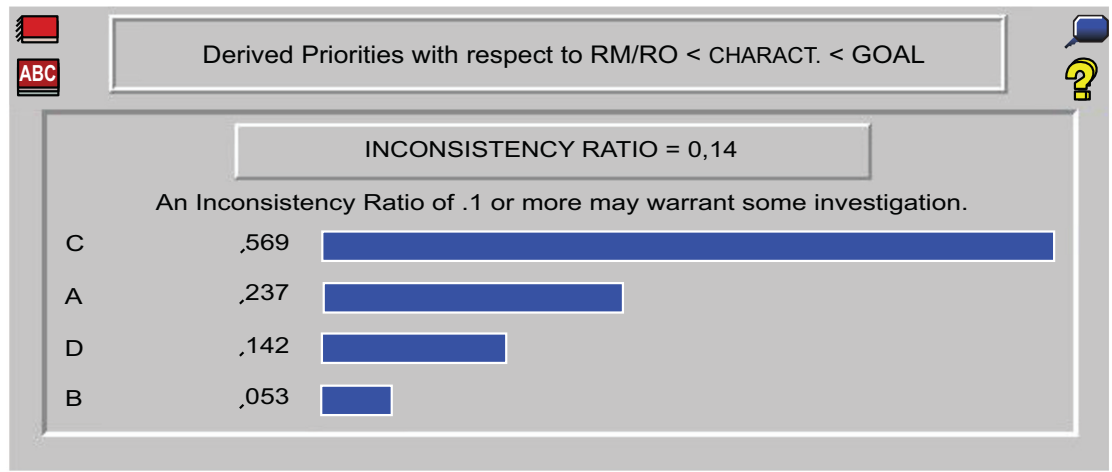

Fig. (4). Comparison matrix for the parameter " $\mathrm{R}_{\mathrm{m}} / \rho$ ", located on the fourth level of the class hierarchy, with priorities and related coefficient of inconsistency. 


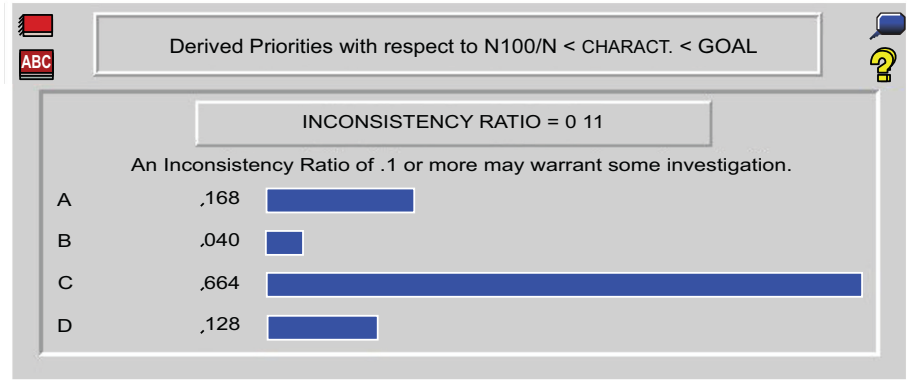

Fig. (5). Comparison matrix for the parameter " $N_{100 \mu \mathrm{m}} / N$ " on the fourth level of the class hierarchy, priorities and related coefficient of inconsistency.

mechanical characteristics and costs needs to be 0.633 and 0.304 respectively.

Figs. $(4,5)$, by way of example, show the comparison tables for some of the parameters residing at the fourth level of the category hierarchy (alternatives), the priorities and the relative coefficient of inconsistency are shown as well.

Fig. (6) gives a summary of the results obtained from the analysis. The company $\mathrm{C}$ turns out to be the most competitive. The company A ranks at the last place.

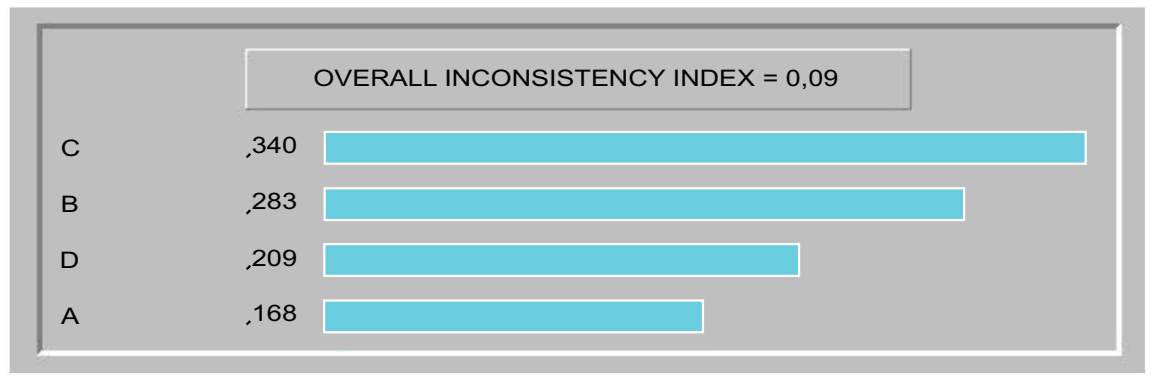

Fig. (6). Obtained results: the company $\mathrm{C}$ turns out to be the most competitive.
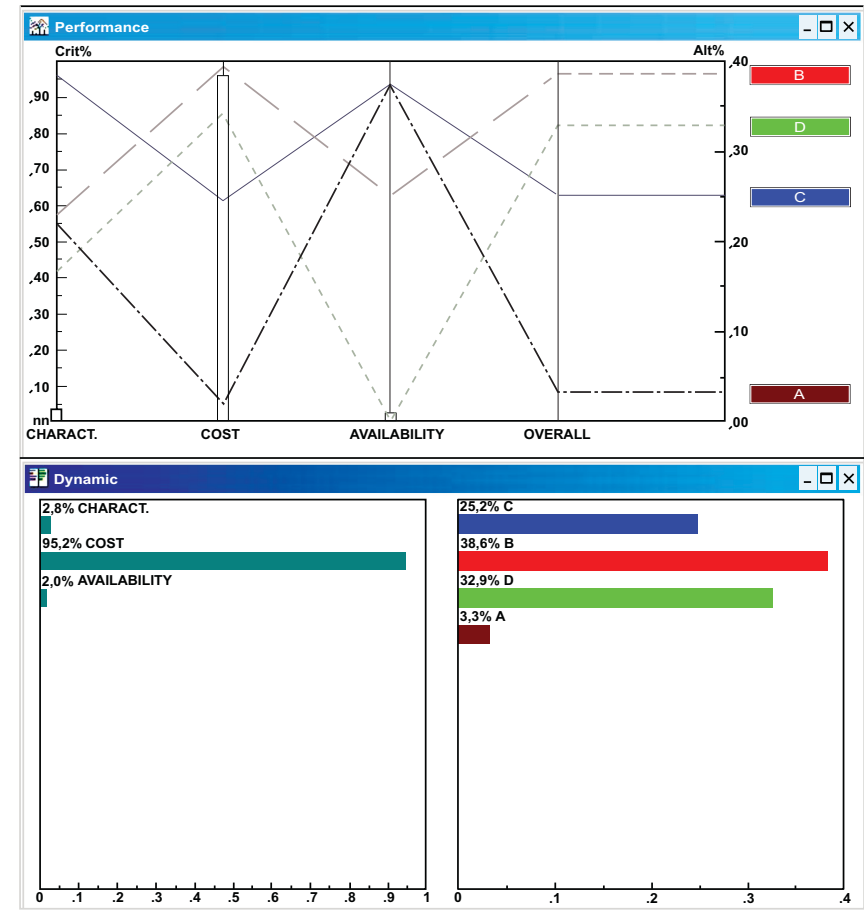

Fig. (7). Sensitivity analysis related to a high weight of the material cost. 
The result is justified by the fact that the assessment of priorities was the criterion used for judging the AHP methodology, and a higher priority was assumed for the mechanical properties, if compared to the cost of the material, as well as the cost of the material with respect to availability.

The result turns out to be highly subjective, and tied to the importance of the value that the user assigns to the
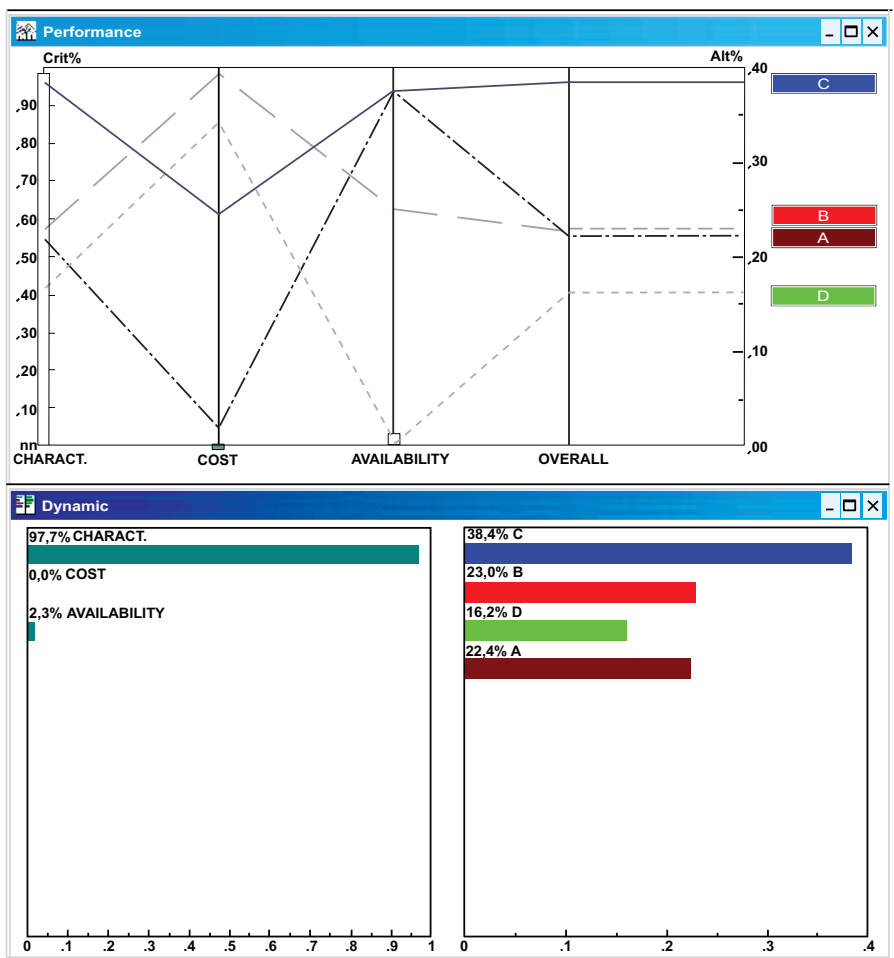

Fig. (8). Sensitivity analysis related to a high weight of the mechanical characteristics.
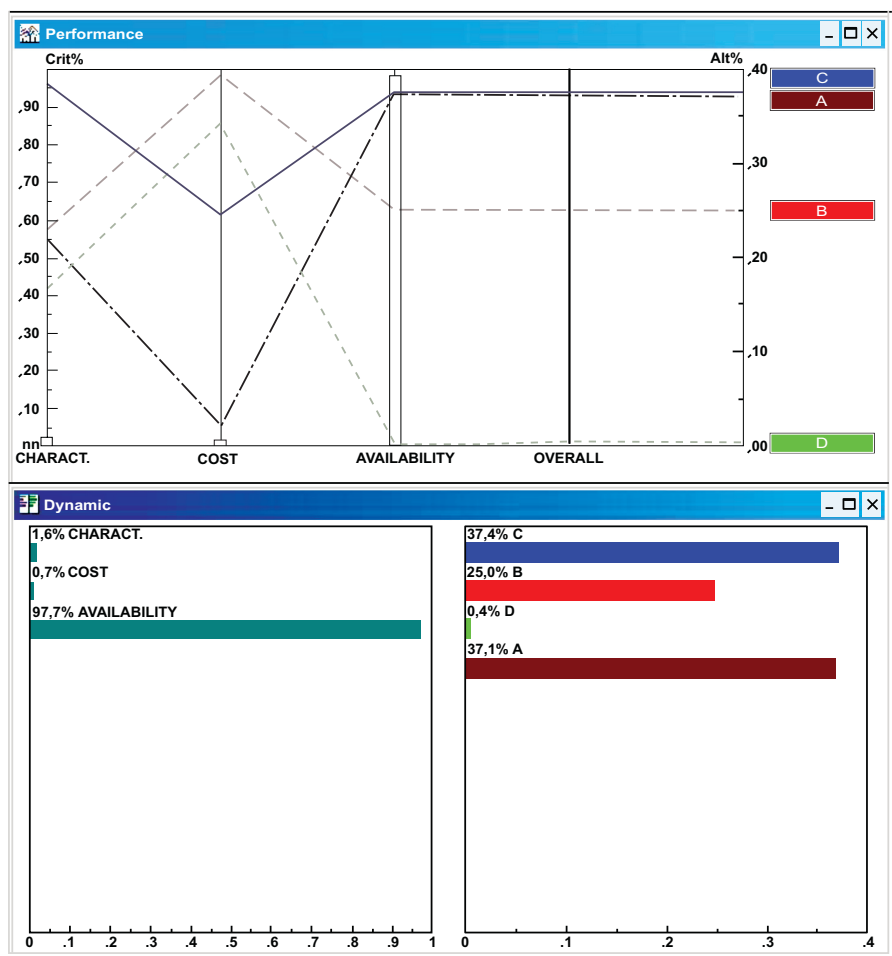

Fig. (9). Sensitivity analysis related to a high weight of the availability of the material. 
different parameters that influence the choice of the material, thus being related to the user experience itself.

A sensitivity analysis of the various parameters can be carried out. By changing the priority of the individual parameters it is possible to evaluate their influence on the final choice. In Fig. (7), the material cost assumes a greater importance, if compared to the other parameters, and in this case the B company is the most competitive.

In Fig. (8), the mechanical characteristics assume a greater importance, if compared to the other parameters, and in this case the $\mathrm{C}$ company is the most competitive.

In Fig. (9), the availability of the material assumes a greater importance, if compared to the other parameters. In this case, the companies $\mathrm{A}$ and $\mathrm{C}$ appear to be the most competitive.

\section{CONCLUSION}

The multi-attribute decision AHP (Analytic Hierarchy Process) procedure was used for the choice of the best levels for the different parametric and non-parametric attributes and to select the best company. Parametric and non-parametric attributes were considered, and the AHP method allowed to choose the most attractive company and to develop the sensitivity analysis with respect to each parameter.

\section{CONFLICT OF INTEREST}

The author confirms that this article content has no conflict of interest.

\section{ACKNOWLEDGEMENTS}

Declared none.

\section{REFERENCES}

[1] Mirandola R, Tuccoli M, Vaglini S, De Risi P. Sistemi qualità, seconda edizione, ETS editrice. Pisa 1991

[2] Geier MH. Quality handbook for composite materials. Chapman \& Hall: New York 1994.

[3] Baragetti S. Qualità nella progettazione e realizzazione di elementi meccanici con rapporto resistenza/massa elevato. Ph.D. Thesis. Firenze 1998.

[4] Saaty LT. How to make a decision: The analytic hierarchy process INTERFACES. 1994; 24(6): 19-43.

[5] Saaty LT. Foundamentals of decision making. RWS Publications. U.S.A. 1994.

[6] Mustafa MA, Al-Bahar JF. Project risk assessment using the analytic hierarchy process. IEEE Trans Eng Mang 1991; 38: 46-52.

[7] Cambron KE, Evans GW. Layout design using the analytic hierarchy process. Comp Indus Eng 1991; 20: 211-29.

[8] Zahir MS. Incorporating the uncertainty of decision judgements in the analytic hierarchy process. Euro J Oper Res 1991; 53: 206-16.

[9] Vargas LG. An Overview of the analytic hierarchy process and its applications. Euro J Oper Res 1990; 48: 2-8.

[10] Schniederjans MJ, Wilson RL. Using the analytic hierarchy process and goal programming for information system project selection. Info Mang 1991; 20: 333-42.

[11] Badiru AB, Foote BL. Chetupuzha J. A multiattribute spreadsheet model for manufacturing technology justification. Comp Indus Eng 1991; 21: 29-33.

[12] Expert Choice, Inc. Expert Choice: Walk-Through. Pittsburgh, Pennsylvania 1990.

[13] Dobias AP. Designing a mouse trap using the analytic hierarchy process and expert choice. Eur J Oper Res 1990; 48: 57-65.

[14] Lloyd DJ. Particle reinforced $\mathrm{Al}$ and $\mathrm{Mg}$ matrix composites. Inter Mat Rev 1994; 39: 1-21

[15] Luster JW, Thumann M, Baumann R. Mechanical properties of aluminium alloy $6061 / \mathrm{Al}_{2} \mathrm{O}_{3}$ composites. Mat Sci Tech 1993; 9(10): 853-62

[16] Duralcan Technical Documents. Duralcan composites for wrought products 1994

This is an open access article licensed under the terms of the Creative Commons Attribution Non-Commercial License (http://creativecommons.org/licenses/ by-nc/3.0/) which permits unrestricted, non-commercial use, distribution and reproduction in any medium, provided the work is properly cited. 